Boletín de la Sociedad Geológica Mexicana

VOLUMEN 67, NÚM. 3, 2015, P. 533-544

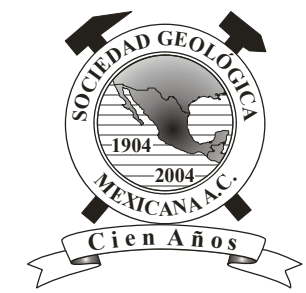

\title{
Control térmico de la meteorización de superficies endurecidas en rocas graníticas (La Pedriza de Manzanares, España)
}

\author{
Manuel García-Rodríguez ${ }^{1, *}$, Miguel Gómez-Heras ${ }^{2}$, Rafael Fort², Mónica Álvarez de Buergo ${ }^{2}$ \\ ${ }^{1}$ Departamento de Ciencias Analíticas, Facultad de Ciencias, Universidad Nacional de Educación a Distancia (UNED). Paseo Senda \\ del Rey 9. 28040, Madrid, España. \\ ${ }^{2}$ Instituto de Geociencias IGEO, CSIC-Universidad Complutense de Madrid, Madrid, España. \\ *manu.garo@ccia.uned.es
}

\section{Resumen}

La Pedriza de Manzanares es parte del Parque Nacional del Guadarrama en el Sistema Central Español. Se caracteriza por formar un paisaje laberíntico constituido por una alternancia de bloques y grandes paredes de granito. Gran parte de las superficies de estas rocas están recubiertas por costras endurecidas de espesores milimétricos, que controlan la alteración superficial y favorecen el desarrollo y distribución de micro-relieves sobre las paredes. Para explicar el proceso de alteración que favorece la formación de irregularidades sobre la superficie del granito, en este trabajo se analizan algunas variables tales como la temperatura, índice de esclerometría y morfología de los micro-relieves. Por otra parte, el artículo establece relaciones entre la primera fase de formación de las superficies endurecidas en condiciones subedáficas, asociada al frente de alteración, con los espesores de las costras endurecidas y la erosión del regolito. Las relaciones definidas y resultados obtenidos son de aplicación en otras regiones graníticas del mundo de características similares.

Palabras clave: Superficies endurecidas, meteorización de granitos, Pedriza de Manzanares, Parque Nacional de Guadarrama.

\begin{abstract}
Pedriza de Manzanares is part of the Guadarrama National Park in the Spanish Central System. It is characterized by a labyrinthine landscape composed of alternating blocks and large walls of granite. Case-hardened crusts of millimetric thickness covering most of these rock surfaces control the surface alteration and favor the development and distribution of micro-reliefs on the walls. Some variables such as temperature, sclerometric index and micro-relief morphology are analyzed in this paper in order to explain the destructive process of alteration that favors the formation of irregularities on the granite surface. On the other hand, the paper establishes the relation between the first stage of case-hardening in sub-edaphic conditions, which is associated with the alteration front, and the thickness of such crusts and regolith erosion. These results can be applied to other granitic regions with similar characteristics all over the world.
\end{abstract}

Keywords: Case-hardening, granite weathering, Pedriza de Manzanares, Guadarrama National Park. 


\section{Introducción}

\subsection{Contexto geológico y objetivo}

La Pedriza de Manzanares se localiza en el Sistema Central Español (en la provincia de Madrid), y define un paisaje eminentemente geológico formando por granitoides entre las cumbres de la sierra de Cuerda Larga y la población de Manzanares el Real. La atractiva geomorfología de este entorno convirtió a la Pedriza en uno de los primeros espacios protegidos españoles, hasta incorporarse recientemente con la Ley 7/2013 de 25 de junio a la declaración del Parque Nacional de Guadarrama.

Los granitoides de la Pedriza intruyeron en la cordillera del Sistema Central Español a finales del Paleozoico durante la orogenia Varisca, alcanzando su posición actual durante la orogenia Alpina que se inició a principios del Terciario. Son leucogranitos formados por feldespato potásico, cuarzo, plagioclasa, y biotita como principal mineral máfico (PérezSoba y Villaseca, 2010).

Este espacio natural comprende dos zonas bien definidas con características mineralógicas y geomorfológicas diferentes, que se conocen como la Pedriza posterior y la Pedriza anterior. La Pedriza posterior incluye las zonas de mayor altitud, comprendida entre 1700 - 1900 metros sobre el nivel del mar (msnm), dando paso a las cumbres de la sierra de Cuerda Larga. La Pedriza anterior, dónde se localiza nuestra zona de estudio, representa el sector más meridional y se extiende desde la localidad de Manzanares el Real, hasta la falla del collado de la Dehesilla - collado Cabrón (SW - NE), que representa un límite natural con la Pedriza posterior. Las alturas de la Pedriza anterior varían entre unos $900 \mathrm{msnm}$ en las proximidades de Manzanares el Real, y 1719 msnm en la cima del Yelmo. En particular, la zona estudiada se sitúa a una altitud de $1180 \mathrm{msnm}$. Según el IGME (1988), el clima en la Pedriza anterior es de tipo Mediterráneo templado-frío, húmedo. La pluviometría media anual en el rango de altitudes de la Pedriza anterior es de $800-1500 \mathrm{~mm} /$ año, con una temperatura media anual de $11-12^{\circ} \mathrm{C}$ en las zonas más bajas de la Pedriza, y de $9-10^{\circ} \mathrm{C}$ para alturas comprendidas entre $1200-1600 \mathrm{~m}$.

El levantamiento alpino ha dado lugar a una vertiente escalonada con relieves grabados, conforme la meteorización penetraba a favor de las fracturas y producía la evacuación de regolito hacia la cuenca del Tajo (Centeno, 1988; Pedraza, 1989). En particular, los afloramientos rocosos actuales pueden atribuirse a la erosión y eliminación del regolito, proceso que tiene lugar desde el Plioceno - Pleistoceno (Molina-Ballesteros et al., 1997; Pedraza et al., 2014). La red de fracturación preferente, heredada de la orogenia Varisca y reactivada durante la orogenia Alpina, es de dirección N-S, ENE-WSW y E-W formando un enrejado ortogonal que condiciona la disposición de los bloques graníticos. Los planos de fracturas tienen buzamientos muy diferentes, desde prácticamente horizontales a verticales. Son también muy frecuentes las fracturas de tipo curvo que favorecen el desarrollo de una morfología de tipo dómica (Pedraza et al., 1989; 2014). La dirección predominante de estos planos curvos es también E-W, con buzamientos hacia el sur, lo que define afloramientos que forman grandes muros y paredes rocosas en esta orientación.

En la Pedriza de Manzanares se encuentran cientos de bloques y paredes de granito cubiertas de superficies endurecidas ricas en sílice, que dan a la roca un aspecto de color blanquecino. A medida que esta superficie milimétrica se va desprendiendo, la roca ofrece tonos rojizos debidos a la oxidación de las biotitas. En trabajos previos se ha podido constatar que las superficies endurecidas en la Pedriza predominan en planos de orientación sur. Este hecho parece tener relación con una etapa avanzada en la formación de costras ya en ambiente aéreo por evaporación, lo que hace del Murito un escenario idóneo para estudiar tanto el origen de las costras como de su proceso de alteración por efecto de cambios de temperatura por insolación.

El trabajo estudia el origen del micro-relieve centimétrico o decimétrico desarrollado en una pared subvertical, que en un trabajo previo (García-Rodríguez et al., 2013) se denominó como "El Murito", de $6 \mathrm{~m}$ de altura, dirección este-oeste y orientación hacia el sur (ver localización en Figura 1). El término micro-relieve empleado, hace referencia a cada uno de los "abultamientos" de la roca que define una zona deprimida más meteorizada, y una zona externa de mayor dureza que suele tener restos de superficies endurecidas. Dicha pared presenta una superficie plana con evidencias de haber estado tapizada prácticamente en su totalidad por una superficie endurecida. La eliminación de la superficie endurecida de la pared rocosa durante el tiempo que lleva expuesta en condiciones aéreas, ha producido una alteración diferencial. Los resultados obtenidos sobre las características geomorfológicas de los afloramientos estudiados son de aplicación en otras regiones graníticas del mundo. Algunos ejemplos de otros países y continentes con zonas graníticas y morfologías similares a las presentes en la Pedriza de Manzanares son: el Parque Nacional de Yosemite en EEUU, Parque Nacional Spitzkoppe en Namibia, la Reserva Natural Val di Mello en Italia (Riley et al., 2012; Goudie y Migon, 1997) o el batolito de Ladakh (India).

El objetivo del artículo es establecer relaciones entre la morfología de las rugosidades formadas por eliminación de la superficie endurecida, con otras variables como la temperatura, orientación, verticalidad de la pared y escorrentía superficial. El trabajo presenta una interpretación geomorfológica previa a la exhumación del afloramiento granítico que relaciona el origen de las superficies endurecidas con la meteorización del granito en condiciones ambientales de enterramiento, y con su posterior exposición a condiciones aéreas tras la erosión y eliminación del regolito.

\subsection{Costras superficiales endurecidas}

El endurecimiento superficial de las rocas es un proceso 


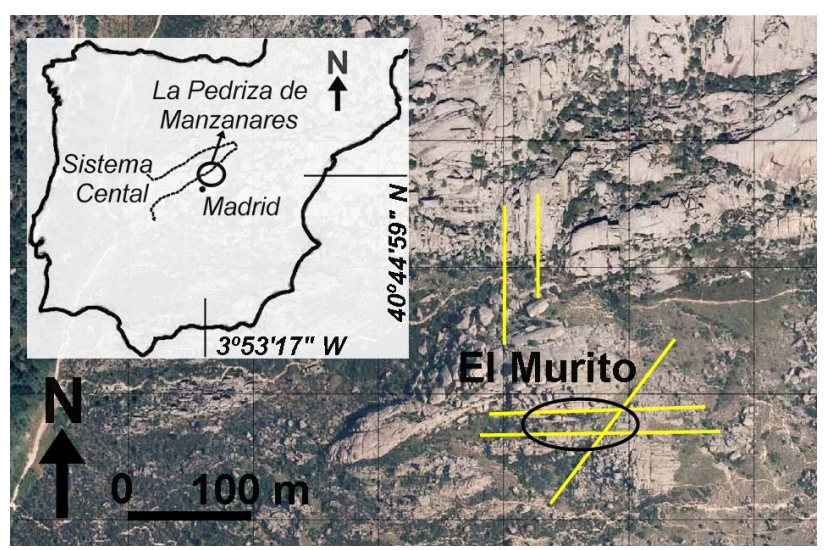

Figura 1. Localización de la Pedriza de Manzanares en el Sistema Central Español con indicación del Murito. El amarillo se representa las principales direcciones de las fracturas de la Pedriza. Fuente: Elaboración propia a partir de imagen de fotografía aérea del Instituto Geográfico Nacional (IGN), Iberpix.

común que afecta a diferentes litologías, creando una costra o superficie endurecida (SE) externa más resistente a la erosión que la parte interior. En la bibliografía pueden encontrarse ejemplos de endurecimientos sobre rocas de diferente naturaleza y en ambientes bioclimáticos también distintos. Por ejemplo, existen trabajos de encostramientos sobre rocas graníticas en Córcega (Wilhelmy, 1964), Australia (Branagan, 1983), Francia y Marruecos (Robinson y Williams, 1987, 1992), así como en muchos otros lugares del mundo. En rocas cristalinas como los granitoides, este tipo de proceso hace que las zonas internas inmediatamente próximas a la costra pierdan cohesión, haciéndose más vulnerables a la erosión (Conca, 1985). Aunque todavía no se conocen muy bien los procesos que intervienen en la formación de algunas de estas costras (Dorn, 1998), la idea más generalizada sobre su origen lo explica por movilización de soluciones de material meteorizado de la roca, bien por capilaridad desde el interior, o por evaporación, precipitando sales sobre la superficie (Garner, 1974; Twidale, 1982; Watson y Pye, 1985). Cuando el origen de la costra se inicia en ambientes aéreos y en condiciones de enterramiento, suele estar formadas por óxidos de hierro y sílice (Merrill, 1906; Mottershead y Pye, 1994) que precipitan sobre planos de fractura internos o sobre las superficies de las rocas (Conca, 1985). En este escenario, Twidale (1982) y Campbell y Twidale (1995) atribuyen esas concentraciones de óxidos de hierro y sílice al frente de alteración subedáfica, donde las concentraciones de hierro comúnmente alcanzan valores de dos a tres veces superiores a las de la roca fresca. El agua de la roca en el frente de alteración puede movilizar sales hacia la superficie, donde las precipita formando una capa o costra endurecida en la parte exterior, y un núcleo más debilitado en la zona interna inmediata a la superficie endurecida (Hobbs, 1912). La relación entre la zona endurecida exterior y la más debilitada interna es fácilmente reconocible cuando la roca aflora y empieza a ser meteorizada (García-Rodríguez y
Centeno, 2014).

La presencia de costras y SE ayuda a proteger las rocas frente a la meteorización y erosión durante periodos de tiempo muy grandes. Cuando la parte endurecida superficial se desprende, el proceso de meteorización avanza con rapidez aprovechando las zonas débiles internas. Esta meteorización diferencial crea micro-relieves o abultamientos sobre la superficie de la roca, con zonas externas que contienen restos de costras de mayor dureza, y zonas de valle (o internas) en las que la superficie endurecida ha desaparecido y la meteorización avanza a mayor velocidad (García-Rodríguez et al., 2014a). La presencia o ausencia de costras sobre superficies graníticas a veces condiciona el desarrollo de otras formas menores típicas de estos materiales. Por ejemplo, cuando la meteorización de la SE penetra a favor de las grietas perimetrales de los agrietamientos poligonales, con frecuencia se forman placas resistentes a la meteorización que quedan separadas hasta varios centímetros de la pared rocosa, formando lo que localmente se conocen como "setas" (Pedraza et al., 1989; García-Rodríguez et al., 2014c). La presencia de agrietamientos poligonales asociados a endurecimientos superficiales es un proceso que afecta a superficies planas de fractura, y también a superficies curvas de bolos graníticos. Cuando los agrietamientos se desarrollan sobre bolos de granito, es frecuente que la placa llegue a desprenderse por completo y se inicie el desarrollo de tafoni en la base del bloque (de Prado, 1975). Como estos tafoni se localizan sobre la zona de menor dureza, más meteorizable, su desarrollo avanza con rapidez en condiciones aéreas.

De acuerdo con trabajos previos realizados por los autores en el denominado Sistema Central Español (GarcíaRodríguez et al., 2012 y 2013), los espesores de las zonas endurecidas y de las zonas de alteración presentes bajo las costras pueden ser muy diferentes dependiendo del tamaño de grano del granitoide, y de que se trate bolos graníticos (Figura 2), o bien sean superficies relacionadas con planos de fractura (Figura 3) que son los que se estudian en este trabajo.

\subsection{Alteración y meteorización}

Los micro-relieves que se estudian en este trabajo tienen relación con la alteración diferencial de los endurecimientos superficiales formados sobre superficies planas de fracturas verticales o subverticales. En términos generales, los mecanismos de alteración de las superficies graníticas se producen por desagregación granular y por desplacado de capas milimétricas paralelas a la superficie de la roca. Los factores externos que más influyen en la alteración de los granitoides tienen relación con procesos en los que la hidrólisis e hidratación son las principales reacciones que contribuyen a su desagregación (Twidale, 1982; Matsukura y Tanaka, 2000). Otros factores que intervienen son el régimen climático y las oscilaciones térmicas (Vidal Romaní y Twidale, 2010), procesos de hielo - deshielo 


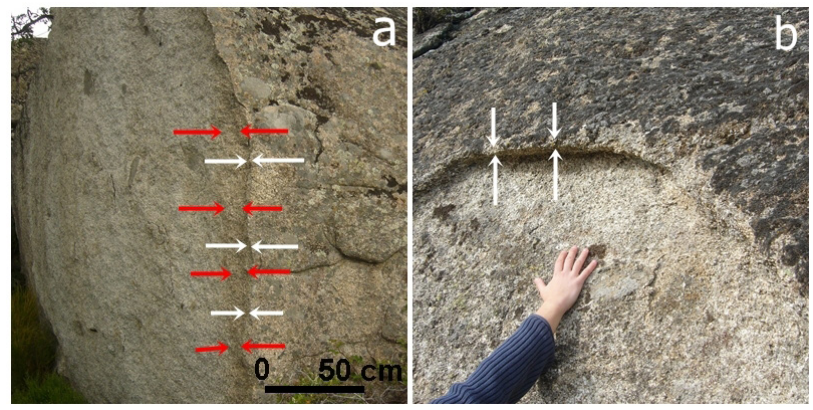

Figura 2. (a) Bolo de granito con indicación de la superficie endurecida exterior (flechas blancas), zona de alteración interna (flechas rojas) y granito inalterado en la zona interna. (b) Detalle de la superficie de un bolo granítico resaltando el espesor de la superficie endurecida más superficial (flechas blancas). Zarzalejo (Madrid).

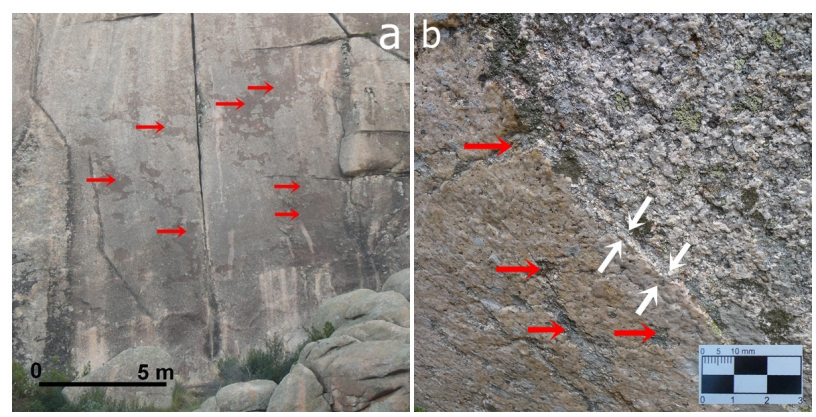

Figura 3. (a) Pared coincidente con un plano de fractura curvo subvertical, cubierto prácticamente en su mayoría por una superficie endurecida de color blanquecino de 2-3 milímetros de espesor. Las flechas rojas indican las zonas en las que la costra se ha desprendido. Los tonos rojizos más oscuros se deben a la oxidación de la biotita. (b) Detalle de una superficie endurecida rica en cuarzo asociada a un plano de fractura. Las flechas rojas indican zonas en las que se ha desprendido la costra. La Pedriza (Madrid).

que intervienen en la rotura de la parte más superficial de la roca (Sosman, 1916; Schulke, 1973; Twidale, 1982), por desecación y rotura de la parte superficial de las rocas debido a la insolación (Robinson y Williams, 1989), o debido a microorganismos (Viles y Goudie, 2004).

La insolación es un agente potencial de meteorización a través de los esfuerzos generados por diferencias de temperatura (Rice, 1976; Smith, 1977, Gómez-Heras et al., 2008), debido a que los cambios térmicos actúan a escala de los granos minerales que componen la roca (Hall y André, 2003; Gómez-Heras et al., 2006). En rocas heterogéneas como es el caso de los granitoides, los cristales que la componen (por ejemplo el cuarzo y el feldespato), tienen diferentes coeficientes de dilatación térmica y responden también de manera distinta ante los cambios de temperatura. Ishimaru y Yoshikawa (2000) y Hall y André, (2003) consideran al gradiente térmico uno de los principales procesos de la micro-descamación de superficies graníticas. Además del efecto mecánico de cambios de temperatura sobre los granos minerales, las modificaciones periódicas de humedad y la cristalización de sales están consideradas como los principales mecanismos responsables de la primera fase de alteración de las superficies de los granitoides (Van Autenboer, 1964; Bradley et al., 1978). Las sales incrementan la solubilidad de los silicatos en periodos húmedos, y cristalizan en periodos secos favoreciendo un proceso de meteorización mixto mecánico y químico (Young, 1987).

El artículo pone de relieve la importancia que tiene la insolación en el proceso de alteración y/o desprendimiento de la superficie endurecida rica en sílice que recubre una pared orientada hacia el sur.

\section{Metodología}

\subsection{Características generales}

En este trabajo se ha monitoreado el Murito desde el suelo hasta una altura de $6.5 \mathrm{~m}$, en una banda de unos $2 \mathrm{~m}$ de anchura (Figura 4). El límite superior de la zona estudiada viene dado por una fractura horizontal que representa una discontinuidad sobre la que apoya un bloque independiente de la zona estudiada. La altura total de la pared, incluyendo el bloque superior, es de $9 \mathrm{~m}$, su dirección Este-Oeste, y su orientación, Sur.

La superficie estudiada, a pesar de corresponder a un mismo plano de fractura original, presenta inclinaciones que varían entre unos $50^{\circ} \mathrm{S}$ en la parte más elevada, justo por debajo del bloque superior, y cerca de $90^{\circ} \mathrm{S}$ en la parte inferior del muro cerca del suelo. Como sobre la superficie de la pared se reconocen varias fracturas paralelas con espaciado variable de entre unos 5 y $50 \mathrm{~cm}$, la banda estudiada tiene continuidad desde el suelo hasta la parte más alta y se corresponde con un mismo plano de fractura. Además, sobre la banda seleccionada se ha identificado continuidad del endurecimiento estudiado. Se han descartado superficies de fractura o lajas de zonas laterales de la banda elegida, que pudieran llevar más o menos tiempo expuestas al efecto de la insolación y de cambios de humedad, y por tanto tener una velocidad de meteorización diferente.

\subsection{Técnicas empleadas}

Las técnicas empleadas para el estudio de los microrelieves han sido las siguientes:

- Análisis e interpretación geomorfológica del Murito desde su origen en condiciones de enterramiento hasta la actualidad en condiciones aéreas.

- Estudio mineralógico de la superficie del Murito diferenciando las zonas de costra y aquellas en las que ha sido eliminada.

- Medida del tamaño y forma de los abultamientos en toda la altura de la pared.

- Registro de la temperatura de la pared con sensores data-loggers (tipo $i$-button) durante un periodo de tiempo de un año. 


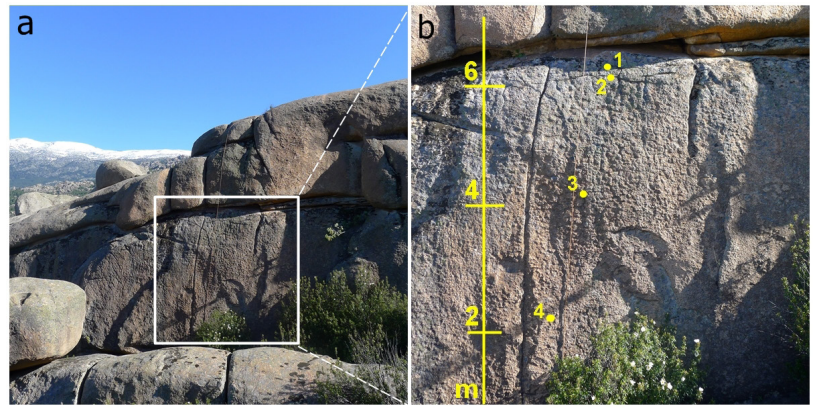

Figura 4. (a) Vista general del Murito (b) Detalle de la zona estudiada con la localización de los i-button.

- Registro de la temperatura mediante empleo de termografía.

- Determinación del índice de esclerometría con martillo Schmidt en las zonas internas y externas de los abultamientos.

\subsubsection{Mineralogía y formas de los micro-relieves}

Debido a la altura y verticalidad del Murito, las medidas se han llevado a cabo mediante técnicas de escalada con cuerdas fijadas en la parte superior de la pared (Figura 5). Las características petrográfico-mineralógicas de las zonas con y sin costra endurecida se determinaron mediante microscopía óptica de polarización por luz transmitida, utilizando para ello un microscopio petrográfico OLYMPUS BX51 con cámara digital acoplada OLYMPUS DP12.

Para conocer el aspecto y distribución de las rugosidades a diferentes alturas, se establecieron intervalos de $0.5 \mathrm{~m}$ en toda la altura de la pared, permitiendo una sistemática en las mediciones. En cada intervalo se midieron las longitudes de los ejes mayor y menor de cada abultamiento (medidos perpendicularmente entre sí), altura con respecto al suelo, inclinación de la pared, y profundidad de los valles entre cada abultamiento. A partir de las medidas de los ejes, se definió un índice de forma como $(M+m) / 2$, siendo $(M)$ el eje mayor y $(m)$ el eje menor.

\subsubsection{Estudio de temperaturas}

El registro de la temperatura se realizó con sensores tipo i-button colocados a diferentes alturas con la finalidad de estudiar variaciones de temperatura a diferentes alturas del Murito, y buscar relaciones con el tamaño de la rugosidad y la presencia de los endurecimientos en la pared. Se realizaron medidas con registro continuo durante un periodo de un año, entre el 15 de septiembre de 2012 y el 15 de septiembre de 2013. Se colocaron cuatro sensores (B1, B2, B3 y B4) sobre la pared del Murito. Los sensores B1 y B2 se colocaron en un agrietamiento poligonal que culmina la pared del murito; el B1 a una altura de $6.2 \mathrm{~m}$ sobre la placa del agrietamiento poligonal, y B2 a $6.1 \mathrm{~m}$ de altura, sobre la grieta. Los sensores B3 y B4 se colocaron a $4.2 \mathrm{~m}$ y a $2.3 \mathrm{~m}$ de altura respectivamente. El estudio del efecto de la temperatura se completó con la realización de

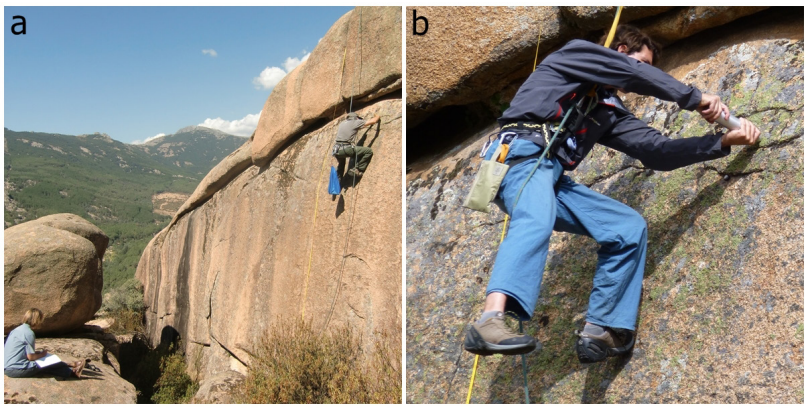

Figura 5. (a) Instalación de sensores i-button. (b) medidas del índice de esclerometría con martillo Schmidt.

una termografía.

La termografía de infrarrojos es una técnica no destructiva en la cual se obtienen las temperaturas superficiales de un objeto a partir de una imagen obtenida en la franja espectral de los infrarrojos (entre 7.5 a $13 \mu \mathrm{m}$ en el caso de la cámara utilizada en este ensayo), basándose en la relación que existe entre la cantidad de energía y su longitud de onda de la radiación emitida por un objeto con la temperatura superficial $(\mathrm{T})$ del mismo.

Existen dos modos de toma de imágenes de infrarrojos: termografía pasiva y activa (Avdelidis y Moropoulou, 2003). En este caso se tomaron una serie de imágenes en modo de termografía activa, es decir, imágenes secuenciales tomadas durante un proceso de calentamiento para observar cómo las diferencias de respuesta térmica divergen entre distintas zonas. En este caso la estimulación térmica viene dada por la radiación solar.

Con la serie de imágenes se realizó un análisis multiimagen de la evolución de las distintas partes del muro durante el calentamiento, en concreto se realizó un análisis de Componentes Principales de Termografía (PCT). Un Componente Principal de Termografía (PCT) es cada una de las combinaciones lineales de las imágenes de la serie, tomadas a intervalos de tiempo iguales, que diagonalizan la matriz de covarianza. El autovalor asociado a cada componente principal es una indicación del porcentaje de la variación total de la temperatura que se puede adscribir a esa combinación lineal de imágenes. De esta forma se puede categorizar la importancia relativa de varios comportamientos simultáneos frente al calentamiento. Los PCT se van numerando sucesivamente (PCT-1, PCT2 , etc.) de mayor a menor influencia en la variación total (Gómez-Heras et al., 2014). Para realizar los cálculos con las imágenes se utilizó la aplicación ir_view (v. 1.7.5) desarrollada bajo el software Matlab (Klein et al., 2008).

Las imágenes de infrarrojos se tomaron cada 15 minutos desde las 10:00 hasta las 12:30 con una cámara ThermaCAM ${ }^{\mathrm{TM}} \mathrm{S} 4$ (rango espectral de 7.5 a $13 \mu \mathrm{m}$, rango de detección de temperaturas de $-20^{\circ} \mathrm{C}$ a $+130^{\circ} \mathrm{C}$, sensibilidad térmica de $0.08^{\circ} \mathrm{C}$ y tamaño de imagen 640 x 480 pixeles) manteniendo el encuadre constante. Se realizaron correcciones de temperatura y humedad ambiente 
así como de distancia. Se utilizó una emisividad fija de 0.96 para toda la imagen y en todas las imágenes puesto que el interés estaba centrado en el análisis multi-imagen de la evolución de las distintas partes de un objeto durante el calentamiento.

\subsection{3. Índice de esclerometría}

Se realizaron medidas de dureza con el martillo Schmidt a lo largo y ancho de toda la banda estudiada de acuerdo con metodologías aplicadas en estudios geomorfológicos con esta instrumentación (Goudie, 2006). En cada intervalo de $0.5 \mathrm{~m}$ se realizaron 5 medidas sobre las zonas exteriores de los abultamientos y otras 5 en las zonas interiores (valle). El índice de esclerometría o de rebote es adimensional y no tiene unidades. En general, las medidas de las zonas externas están realizadas sobre restos de superficies endurecidas y las interiores en zonas más meteorizadas en las que ha desaparecido el endurecimiento (Figura 5b).

\section{Resultados y discusión}

El granito objeto de este estudio es un leucogranito con tamaño de grano de grueso a medio, formado por cristales de cuarzo, ortosa, microclina, plagioclasa, y biotita subidiomorfa y alotriomorfa, en un porcentaje entre el $2-5$ $\%$. La cementación por óxidos de hierro de las fisuras inter e intracristalinas de estas rocas se debe a la alteración de las biotitas (Figura 6a y 6b).

Existen minerales secundarios o productos de alteración meteórica, como moscovita, clorita y sericita. En las zonas más superficiales del granito se aprecia una mayor fisuración de los cristales de cuarzo y la cementación de óxidos de hierro es menor en las zonas más internas de la roca. Estas fisuras son de varios milímetros de longitud y presentan aperturas que pueden llegar a los $0.2 \mathrm{~mm}$ (Figura 6c y 6d). Estas fisuras pueden ser subparalelas a la superficie o incluso perpendiculares a la superficie y suelen estar rellenas con cuarzo. El resultado de las láminas con una zona exterior o superficie endurecida (SE) a modo de encostramiento con una mayor proporción de sílice apoya y confirma en parte, las ideas enunciadas por Campbell y Twidale (1995), sobre el origen de estas costras asociadas al frente de alteración en condiciones edáficas o subterráneas y que continúan desarrollándose en condiciones aéreas por procesos de evaporación.

Los resultados obtenidos de la interpretación de las láminas delgadas en las zonas externa e interna del granito, junto con el estudio de las direcciones y buzamientos de la red de fracturación que controla el paisaje de la Pedriza anterior (García-Rodríguez et al., 2013) y del Murito en particular, ha permitido desarrollar y proponer un modelo conceptual del origen de la pared estudiada desde sus inicios en condiciones subaéreas hasta la actualidad (Figura 8).

El modelo de alteración propuesto (Figura 8) responde a un modelo clásico del proceso de exhumación del granito

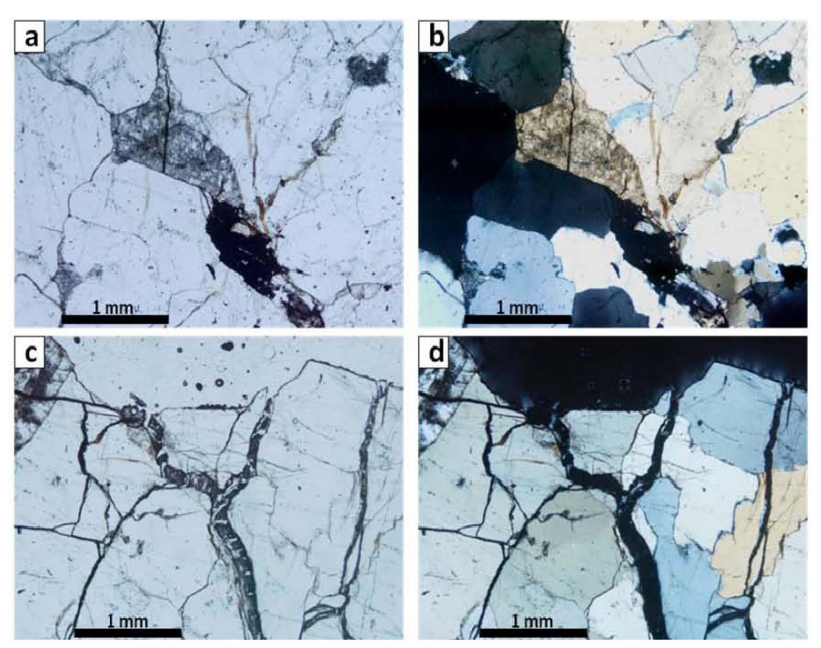

Figura 6. Aspecto al microscopio de polarización del leucogranito. a y c, nicoles paralelos; b y d nicoles cruzados. ( $\mathrm{a}$ y $\mathrm{b}$ ) a unos $2 \mathrm{~cm}$ de profundidad donde se aprecia la alteración de un feldespato potásico (ortosa) y una biotita que su alteración da lugar a óxidos de hierro que cementan fisuras. (c y d) imágenes de la superficie del leucogranito con procesos de fisuración de los cuarzos y presencia de cementación posiblemente de sílice.
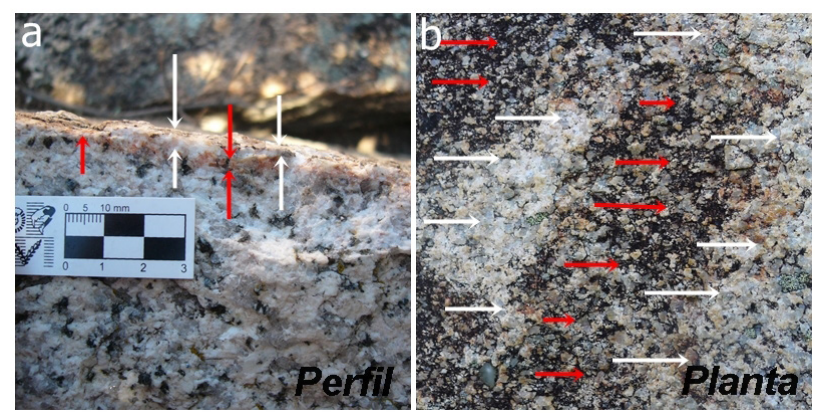

Figura 7. (a) Corte de roca con indicación de: Superficie endurecida rica en sílice en la parte exterior (flechas blancas), zona alteración situada inmediatamente por debajo de la superficie endurecida (flechas rojas) y zona de granito inalterado en la zona más interna. (b) Imagen de una superficie de granito con indicación de zonas endurecidas (flechas blancas) y zonas en la que la superficie endurecida se ha eliminado, más meteorizada. La Pedriza de Manzanares (Madrid).

(Figura 8a) ya definido por (Twidale, 1982), pero que incorpora una nueva interpretación sobre el desarrollo de AP en la parte superior del Murito (Figura $8 \mathrm{~b}$ ), la cual que puede atribuirse a una meteorización diferencial a favor de un sistema de fracturas preexistentes (García-Rodríguez et al., 2014b). El modelo descrito también explica el desarrollo de micro-relieves con distinta profundidad, siendo la misma menor en las zonas próximas al suelo (Figura $8 \mathrm{~b}$ ).

El estudio por tramos en altura de la pared del Murito permite diferenciar cuatro zonas de características algo diferentes, según la morfología de los micro-relieves identificados (Tabla 1) y del índice de esclerometría medido (Tabla 2). El índice de esclerometría o rebote es adimensional y no tienen unidades. Estas zonas son:

Zona 1: Se localiza entre 6 y $6.5 \mathrm{~m}$ de altura. Tiene agrietamientos poligonales (AP) de tipo cuadrangular muy 

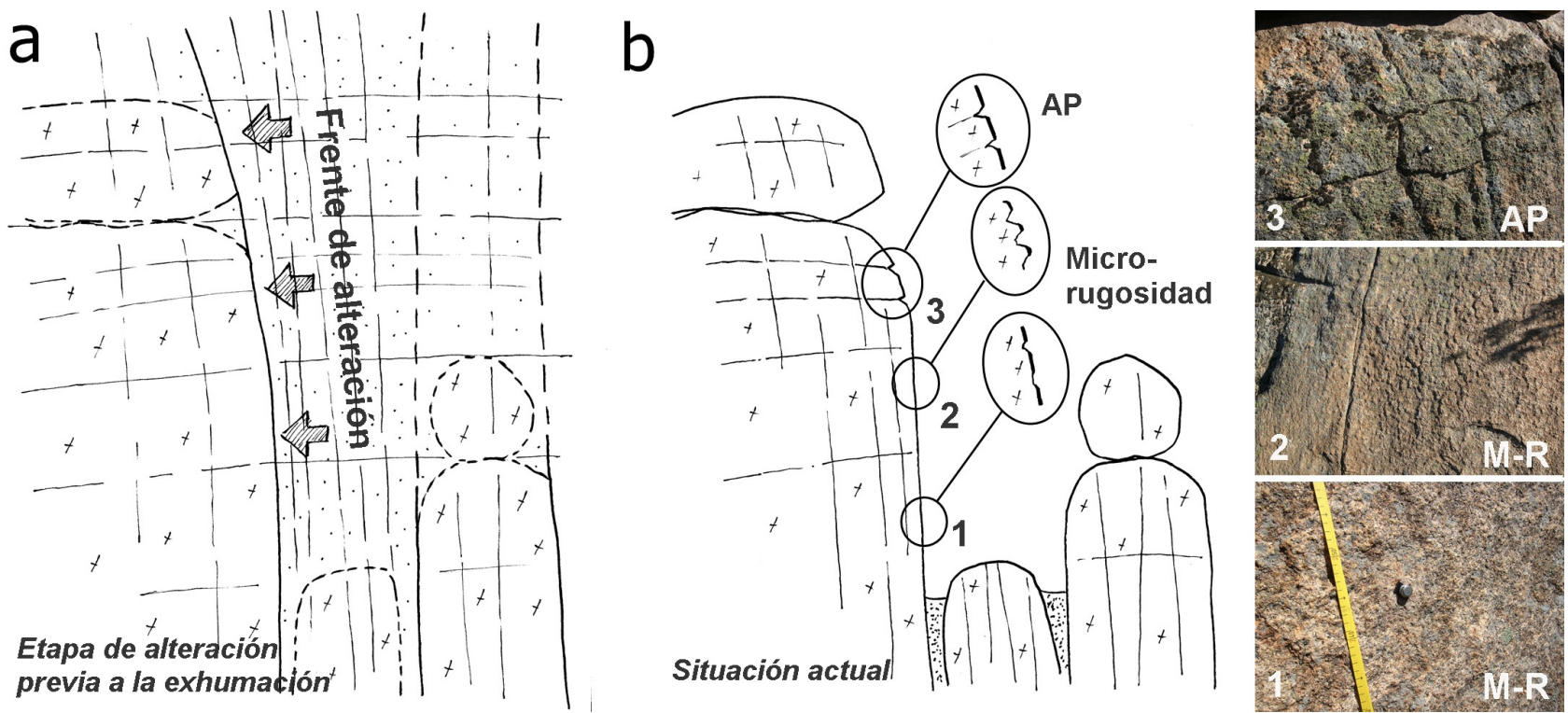

Figura 8. (a) Red de fracturación y evolución del frente de alteración en condiciones subaéreas en la superficie y plano de fractura que forma la actual pared del Murito, (b) Representación esquemática del perfil de Murito con indicación y localización de los agrietamientos poligonales (AP) y microrelieves (M-R), con detalles en las fotos 1, 2 y 3.

Tabla 1. Distribución y parámetros identificativos de agrietamientos poligonales y micro-relieves en el Murito.

\begin{tabular}{lccccc}
\hline \multicolumn{1}{c}{ Forma / Alt. (m) / N } & $\mathbf{P}^{\left({ }^{\circ}\right)}$ & $\begin{array}{c}\text { E. M } \\
(\mathbf{m m})\end{array}$ & $\begin{array}{c}\text { E. m } \\
(\mathbf{m m})\end{array}$ & F. forma & $\begin{array}{c}\text { Incisión } \\
(\mathbf{m m})\end{array}$ \\
\hline $\mathrm{AP} / 6-6.5 / 9$ & $52^{\circ} \mathrm{S}$ & 443 & 217 & 330 & $10-25$ \\
$\mathrm{AP}, \mathrm{M}-\mathrm{R} / 5.5-6 / 11$ & $71^{\circ} \mathrm{S}$ & 103 & 71 & 87 & $2-10$ \\
$\mathrm{D} / 5-5.5 / 7$ & $75^{\circ} \mathrm{S}$ & 94 & 50 & 72 & $2-4$ \\
$\mathrm{M}-\mathrm{R} / 4.5-5 / 9$ & $77^{\circ} \mathrm{S}$ & 94 & 42 & 68 & $4-6$ \\
$\mathrm{M}-\mathrm{R} / 4-4.5 / 9$ & $82^{\circ} \mathrm{S}$ & 121 & 78 & 99 & $4-6$ \\
$\mathrm{M}-\mathrm{R} / 3.5-4 / 10$ & $84^{\circ} \mathrm{S}$ & 62 & 39 & 51 & $4-6$ \\
$\mathrm{M}-\mathrm{R} / 3-3.5 / 10$ & $84^{\circ} \mathrm{S}$ & 62 & 37 & 49 & $2-5$ \\
$\mathrm{M}-\mathrm{R} / 2.5-3 / 10$ & $84^{\circ} \mathrm{S}$ & 47 & 29 & 38 & $2-3$ \\
$\mathrm{M}-\mathrm{R} / 2-2.5 / 8$ & $86^{\circ} \mathrm{S}$ & 64 & 41 & 52 & $2-3$ \\
$\mathrm{D} / 0-2.5 / 0$ & $88^{\circ} \mathrm{S}$ & - & - & - & $2-3$ \\
\hline
\end{tabular}

Forma: Agrietamiento poligonal (AP), micro-relieve (M-R), difusa (D); Alt.: indica la altura del intervalo medido (en metros); $\mathrm{N}$ es el número de medidas realizadas en cada intervalo.

Parámetros identificativos: pendiente y orientación de la pared (P), tamaño medio de los ejes mayores del intervalo (E. M), tamaño medio de los ejes menores del intervalo (E. m), factor de forma medio del intervalo (F. forma), profundidad de incisión (Incisión).

bien definidos con una geometría que guarda relación con la red de fracturación interna (García-Rodríguez et al., 2014b), con bordes laterales relacionados con fracturas verticales de dirección norte-sur, y bordes superiores e inferiores asociados a planos de fracturas horizontales. Se trata de la zona con menor inclinación, siendo la media del tramo de $52^{\circ}$. La menor pendiente de esta zona puede atribuirse a una zona de mayor meteorización en condiciones de enterramiento, al localizarse en las proximidades de la intersección de un sistema de fracturas verticales y horizontales muy bien definidas. Las placas de los agrietamientos presentan superficies endurecidas muy bien conservadas (Figura 9). El índice de esclerometría sobre las
Tabla 2. Índice de esclerometría medio (IE) y relación del área ocupada por superficie endurecida (SE) y zona alterada (ZA) en el Murito.

\begin{tabular}{cccccc}
\hline Zona & Alt. (m) / N & IE (Ex) & IE (In) & Ex - In & $\begin{array}{c}\text { SE / ZA } \\
(\%)\end{array}$ \\
\hline Z.1 & $6-6.5 / 5$ & 40 & 30.8 & 9.2 & $90 / 10$ \\
Z.2 & $5.5-6 / 5$ & 27.4 & 25.2 & 2.2 & $60 / 40$ \\
& $5-5.5 / 5$ & 36.6 & 29 & 7.6 & $20 / 80$ \\
& $4.5-5 / 5$ & 38.2 & 23.6 & 14.6 & $30 / 80$ \\
Z.3 & $4-4.5 / 5$ & 37.6 & 29 & 8.6 & $40 / 60$ \\
& $3.5-4 / 5$ & 44 & 25.6 & 18.4 & $40 / 60$ \\
& $3-3.5 / 5$ & 31.2 & 25.4 & 15.8 & $55 / 45$ \\
& $2.5-3 / 5$ & 38.4 & 25.8 & 12.6 & $70 / 30$ \\
Z.4 & $2-2.5 / 4$ & 27.5 & 26 & 1.5 & $80 / 20$ \\
& $1.5-2 / 5$ & 36 & 25.7 & 10.3 & $80 / 20$ \\
& $0-1.5 / 4$ & 28.2 & 23.8 & 4.4 & $?$ \\
& Media & 35.0 & 26.4 & 9.6 & \\
\hline
\end{tabular}

Altura en metros (Alt.), número de medidas (N), parte exterior del micro relieve (Ex), parte interior del micro - relieve (In), diferencia del IE entre parte exterior e interior (Ex - In).

placas de los agrietamientos medida con el martillo Schmidt tiene un valor de 40 , ofreciendo los valores máximos registrados de toda la pared (Tabla 2). Se trata por tanto de la zona en la que el endurecimiento superficial alcanza el mayor espesor, atribuible al proceso de alteración en condiciones de enterramiento en una zona de confluencia de fracturas. La incisión de la grietas de los AP oscila entre 1 y $2.5 \mathrm{~cm}$ de profundidad, atribuible a su desarrollo en condiciones aéreas.

Zona 2: Entre los $5 \mathrm{~m}$ y $6 \mathrm{~m}$ la pared muestra una zona de transición entre los agrietamientos poligonales de la parte superior y las rugosidades de la zona inferior. La inclinación media del tramo es de $73^{\circ}$. Entre $5.5 \mathrm{~m}$ y 6 $\mathrm{m}$, los valores medios de dureza en las zonas exteriores e interiores de los abultamientos son muy similares, 


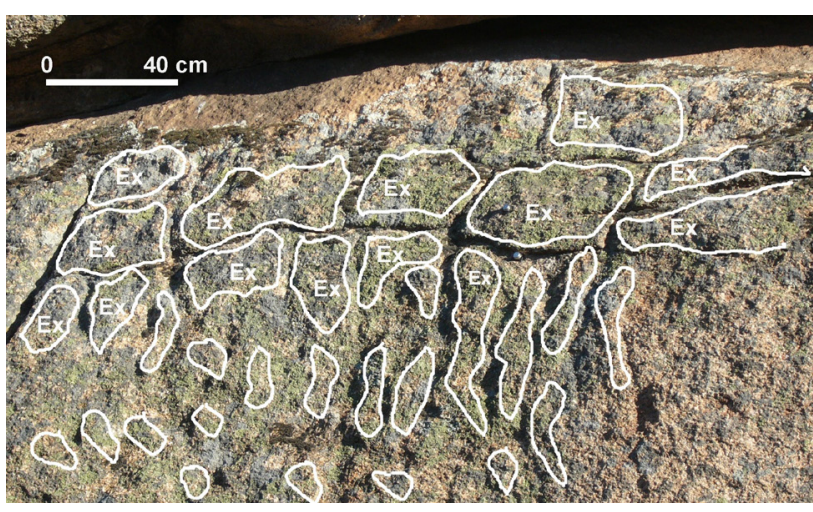

Figura 9. Distribución de superficies endurecidas en las placas de los AP y en las zonas exteriores de los abultamientos de los M-R en el Murito (5 a $6.5 \mathrm{~m}$ de altura).

unos 27 y 25 respectivamente, indicando prácticamente la total desaparición de la superficie endurecida en ese tramo (Tabla 2). Se trata del tramo más meteorizado de todo el muro. En particular, la pérdida del endurecimiento superficial puede atribuirse principalmente al efecto de la escorrentía superficial canalizada desde los bordes laterales de los agrietamientos de la parte superior. Esta escorrentía queda reflejada diseñando formas de incisión alargadas en el sentido de la pendiente. Inmediatamente por debajo, entre $5 \mathrm{~m}$ y $5.5 \mathrm{~m}$, se empiezan a reconocer irregularidades que forman abultamientos aislados, en los que se registra un aumento de la dureza debido a la preservación de la superficie endurecida en las partes exteriores.

Zona 3: Se sitúa entre unos $3.5 \mathrm{~m}$ y $5 \mathrm{~m}$ de altura, con profundidades de los abultamientos de 4 a $6 \mathrm{~mm}$ (Figura 10a). La inclinación del tramo varía de unos $77^{\circ}$ en la parte superior, a unos $84^{\circ}$ en la inferior. Los endurecimientos presentes sobre las zonas exteriores de los abultamientos tienen un índice de esclerometría con valores medios que oscilan entre 31 y 44 (Tabla 2). Los valores de dureza en las zonas interiores, en las que ha desaparecido el endurecimiento, oscilan entre 23 y 29 . La incisión que forma las irregularidades se realiza fundamentalmente a favor líneas verticales por escorrentía superficial del agua. Esta direccionalidad con ejes máximos de gran tamaño entre $4 \mathrm{~m}$ y $4.5 \mathrm{~m}$ de altura presenta un factor de forma de 99 .

Zona 4: Entre el punto de origen y los $3.5 \mathrm{~m}$ de altura existe una superficie endurecida con una incisión de 2 o 3 $\mathrm{mm}$, inferior a la de los tramos superiores donde la presencia de abultamientos es muy escasa (Figura 10b). En este tramo la superficie endurecida tiene mayor continuidad espacial y los abultamiento generados por meteorización de la roca son menos frecuentes.

El registro de temperaturas en la pared durante todo un año indica oscilaciones térmicas diarias, en días despejados, de entre unos 20 y $35^{\circ} \mathrm{C}$ con temperaturas mínimas de unos $0^{\circ} \mathrm{C}$ y máximas de $52^{\circ} \mathrm{C}$, según la época del año. En la Tabla 3 se presenta un resumen de las temperaturas registradas en los periodos 22 de noviembre al 21 de

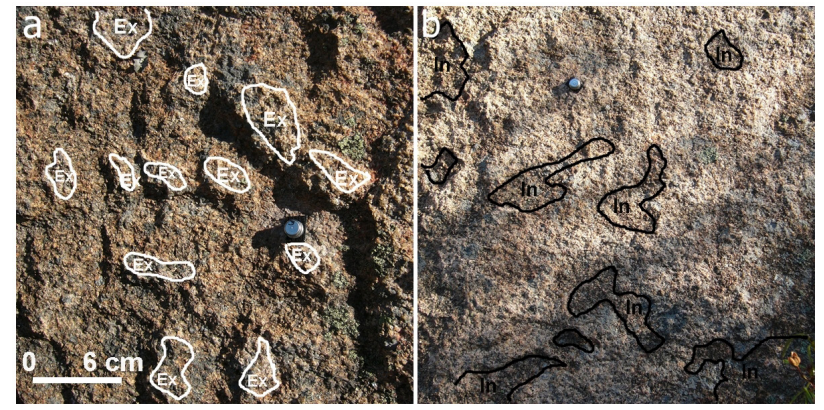

Figura 10. (a) Distribución de superficies endurecidas en las zonas exteriores de los abultamientos del Murito entre 4 y $5 \mathrm{~m}$ de altura. (b) Distribución de las zonas alteradas sin superficies endurecidas entre 1.5 y $2.5 \mathrm{~m}$ de altura.

diciembre de 2012 y del 30 de mayo al 28 de junio de 2013. Se han seleccionado estos periodos de tiempo que incluyen los días más cortos y más largos del año. Además, se trata de una serie de días seguidos sin precipitaciones, lo que proporciona fiabilidad en la interpretación de los datos de temperatura por insolación. La Tabla 3 también incluye las temperaturas máximas y mínimas diarias de un día concreto de cada periodo (Figura 11). El estudio de las diferencias de temperaturas diarias en ambos periodos indica una tendencia decreciente con la altura de la pared.

En la zona superior del Murito, en los AP, se ha observado una diferencia de temperatura diaria entre la superficie de la placa (B1) y zona de grieta (B2) de hasta $5^{\circ} \mathrm{C}$ en diciembre (Figura 11), con valores mayores en B2, donde la pared es más vertical. En junio (Figura 11), cuando los rayos solares inciden más verticalmente, la diferencia de temperatura entre la superficie de la placa (B1) y la grieta (B2) tienden a igualarse aunque los máximos se alcanzan sobre la placa (B1). De un análisis conjunto de las variaciones de temperatura en toda la pared del Murito, dejando aparte los datos del B1 que se localizan sobre una superficie de menor inclinación, se observa que la temperatura registrada durante el mes de enero aumenta con la altura de la pared. En junio las temperaturas tienden a igualarse, aunque los máximos se alcanzan en las zonas más altas y los mínimos en las de menor altura.

Las imágenes de PCT (Figuras 12 y 13) mostradas corresponden a los cuatro primeros componentes (aquellos con un porcentaje sobre la variación total mayor de $5 \%$ ). Las imágenes tiene un filtrado con un filtro gaussiano con una varianza de 0.05 , siendo los porcentajes PCT-1: $49.9 \%$, PCT-2: $16.9 \%$, PCT-3: $8.7 \%$, PCT-4: $5.7 \%$. Colores más oscuros en la imagen significan una mayor variabilidad con respecto a ese componente.

El PCT-1 (Figura 12a) muestra la influencia del régimen general de insolación sobre este muro, con dos áreas en sombra, una oblicua y una vertical, que corresponden a ondulaciones de la superficie. En particular, B3 se localiza en la banda oblicua, donde se inicia un cambio de pendiente de la pared, en la que los micro-relieves alcanzan su máximo 
Tabla 3. Resumen de datos de temperatura en el Murito. Periodos del $22 / 11 / 2012$ a $21 / 12 / 2012$ y del $30 / 05 / 2013$ a 28/06/2013, y días $8 / 12 / 2012$ y $24 / 06 / 2013$.

\begin{tabular}{|c|c|c|c|c|c|c|c|c|}
\hline \multicolumn{5}{|c|}{$\mathrm{T}\left({ }^{\circ} \mathrm{C}\right)$ periodo $22 / 11 / 2012-21 / 12 / 2012$} & \multicolumn{4}{|c|}{ T $\left({ }^{\circ} \mathrm{C}\right)$ día 8/12/2012 } \\
\hline & B1 & B2 & B3 & B4 & B1 & B2 & B3 & B4 \\
\hline Máxima & 31 & 36 & 34 & 31 & 27 & 32 & 31 & 28 \\
\hline Mínima & 1 & 1 & 1 & 1 & 4 & 4 & 4 & 4 \\
\hline Diferencia & 30 & 35 & 33 & 30 & 23 & 28 & 27 & 24 \\
\hline Media & 9 & 9 & 8 & 8 & 15 & 18 & 17 & 16 \\
\hline \multicolumn{5}{|c|}{$\mathrm{T}\left({ }^{\circ} \mathrm{C}\right)$ periodo $30 / 05 / 2013-28 / 06 / 2013$} & \multicolumn{4}{|c|}{ T $\left({ }^{\circ} \mathrm{C}\right)$ día $24 / 06 / 2013$} \\
\hline & B1 & B2 & B3 & B4 & B1 & B2 & B3 & B4 \\
\hline Máxima & 54 & 52 & 53 & 51 & 39 & 38 & 37 & 34 \\
\hline Mínima & 5 & 6 & 5 & 5 & 13 & 14 & 14 & 12 \\
\hline Diferencia & 49 & 46 & 48 & 46 & 26 & 24 & 23 & 22 \\
\hline Media & 21 & 21 & 21 & 20 & 26 & 26 & 25 & 23 \\
\hline
\end{tabular}
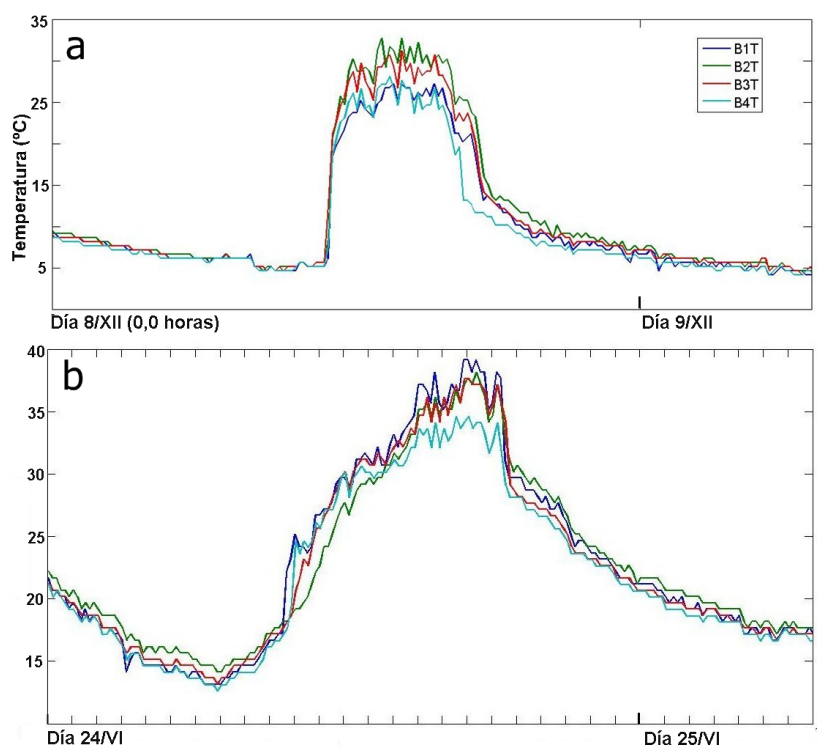

Figura 11. Distribución de temperaturas correspondientes a los días (a) 8 de diciembre de 2012 y (b) 24 de junio de 2013 (datos en Tabla 3).

desarrollo. En el PCT-2 (Figura 12b) los tonos más oscuros indican mayor variabilidad de temperatura, localizados en la parte superior del muro como consecuencia del cambio de pendiente. Se observa así un aspecto parcheado que está relacionado con la presencia de agrietamientos, indicando que la existencia y geometría de las placas endurecidas de los agrietamientos poligonales, ejercen la mayor influencia en la variabilidad térmica después de la morfología a gran escala del muro. Salvando la franja ocupada por los agrietamientos poligonales, y la que queda justo por debajo, la zona superior (entre 5 y $5.5 \mathrm{~m}$ ) es la que presenta menor superficie ocupada por encostramientos, lo que parece lógico si tenemos en cuenta, como ya se ha señalado, que las zonas con más cambios de temperatura contribuyen al desprendimiento de dichos endurecimientos.

En los PCT-3 (Figura 13a) y PCT-4 (Figura 13b) la influencia del material se desdibuja y se manifiestan las variaciones relacionadas con la cubierta vegetal y las sombras proyectadas por esta.

El análisis conjunto de los procesos que han intervenido en la formación y posterior alteración de la pared del Murito, al igual que la de muchas otras paredes en ambientes graníticos, permite extraer conclusiones referentes al origen de los endurecimientos superficiales así como de la influencia que tienen los cambios de temperatura en los procesos de meteorización y desplacado de las superficies endurecidas. En primer lugar y en relación con el origen de estas SE, es precisamente en la parte superior dónde se localizan los mayores espesores, que tienen los valores de los índices de esclerometría más altos, quedando representadas actualmente en las placas de los AP. Este hecho puede atribuirse en primera instancia a una zona de máxima alteración en la etapa de origen subedáfico, donde intersecta un sistema de fracturas ortogonales bien definidas, que continuó desarrollándose en condiciones aéreas por un proceso de evaporación y movilización de sílice que ha estado actuando durante mucho tiempo. La parte inferior del Murito presenta costras endurecidas de menor espesor que se puede relacionar con un frente de meteorización menos activo (con menos fracturas) y un periodo de exposición a la insolación inferior que la parte superior del muro.

En segundo lugar y referente a la alteración de la superficie endurecida, se ha podido comprobar que la insolación representa un factor importante en su deterioro y desprendimiento, ya sea directamente o por su influencia indirecta en otros agentes de meteorización. En general, en las zonas con mayor amplitud térmica (zonas alta y media) se ha perdido mayor superficie de costra que en las partes inferiores del muro, salvando la excepción que representa el mayor espesor de la zona superior de los AP. Exceptuando la particularidad de los agrietamientos poligonales de la parte superior, que forman una franja independiente con otro patrón evolutivo condicionado por un origen algo diferente, los datos de temperaturas en la pared y el análisis de componentes principales de las imágenes de termografía indican que la mayor rugosidad y pérdida de encostramiento está relacionada con las zonas de mayor oscilación de temperatura (zonas altas). Aparte de la influencia indirecta de la insolación en otros agentes de meteorización, como por ejemplo las sales, se podría pensar que la orientación de los cementos de cuarzo que forman la superficie endurecida (que forman empalizadas con el eje "c" perpendicular a la pared), podría favorecer el despegue y posterior desplacado de estas superficies debido a las diferencias en la dilatación térmica del eje "c" y los ejes "a" y "b" de este mineral.

La interpretación de los valores del índice de esclerometría pueden suministrar información sobre el espesor de las superficies endurecidas en diferentes partes del Murito, alcanzando valores mayores en las placas de los AP, menores en la zonas alteradas de valle de los M-R, e intermedios en zonas de costra de poco espesor (como las presentes en los metros inferiores del Murito). Este argumento tiene relación con el hecho que, en las zonas más elevadas de las paredes, que suelen presentar menor 

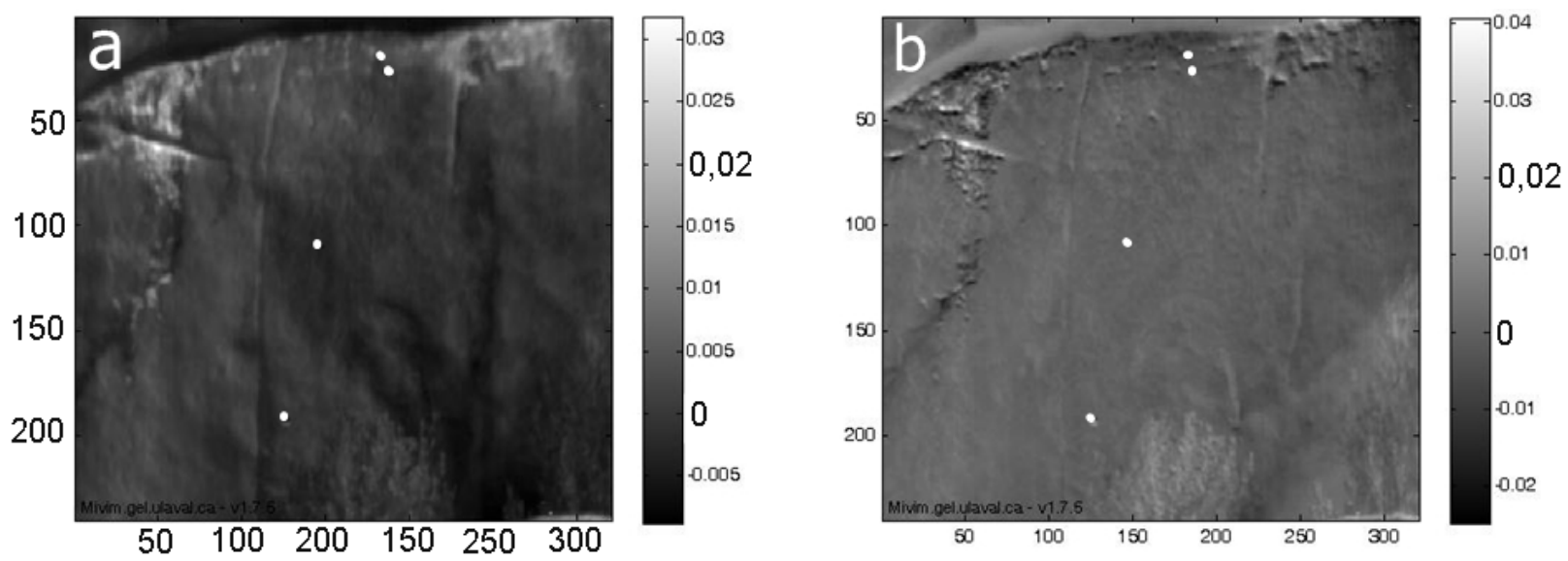

Figura 12. (a) PCT-1, (b) PCT-2. Los puntos blancos indican la ubicación de los i-button (B1, B2, B3 y B4).
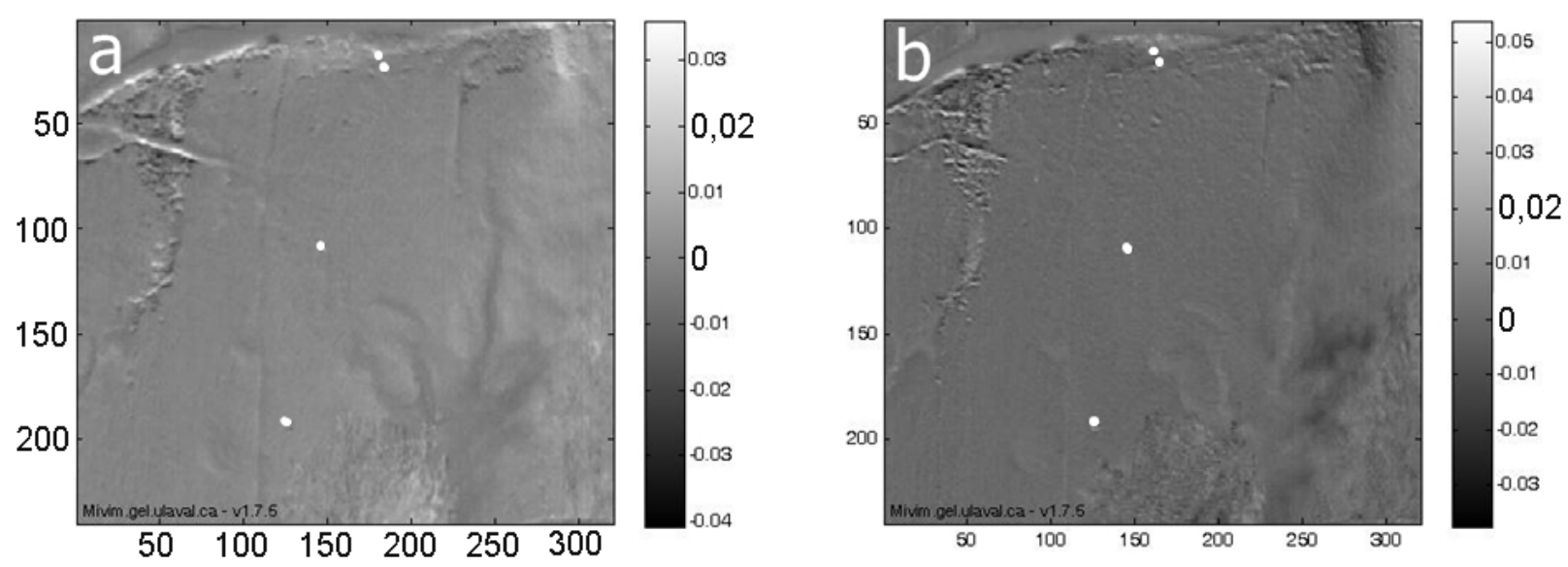

Figura 13. (a) PCT-1, (b) PCT-2. Los puntos blancos indican la ubicación de los i-button (B1, B2, B3 y B4).

inclinación, los procesos de evaporación actúan durante más tiempo, especialmente en las estaciones cálidas, y favorecen el desarrollo de SE con más espesor que en las zonas más verticales y situadas a menor altura. Esta observación, medida e interpretada en el Murito, no representa un hecho aislado sino que se trata una situación muy frecuente en paredes graníticas asociadas a superficies dómicas (Riley et al., 2012; García-Rodríguez et al., 2014c).

Ejemplos con nombre propio de otras paredes graníticas de la Pedriza, también con orientación Sur, en las que se mantiene el esquema descrito; AP bien desarrollados en la parte superior, M-R en la zona central y SE poco meteorizadas cerca del suelo, pueden encontrarse en El Hueso (García-Rodríguez et al., 2014c), El Pájaro, Risco de los Principiantes, Cancho de los Brezos, etc.

\section{Conclusiones}

La pared rocosa del El Murito muestra una costra parcialmente destruida pero con una cierta organización en el progreso de la alteración. En el tramo inferior la costra está bien conservada, es bastante continua y con escaso nivel de agrietamientos. En el tramo superior la costra muestra un agrietamiento poligonal típico, indicador de procesos de migración de solutos y de cierto progreso de la alteración que ha sido activo durante un periodo de tiempo superior al del tramo inferior. Por otra parte, el desarrollo de las grietas perimetrales de las placas de los agrietamientos poligonales ha tenido lugar a favor de fracturas preexistentes perpendiculares a la pared. En el tramo medio-alto, por debajo de los agrietamientos poligonales, la costra está bastante destruida como consecuencia de un drenaje diferencial de la escorrentía, la cual se canaliza por las grietas perimetrales donde la humedad permanece durante más tiempo. En el tramo medio, la alteración superficial ha eliminado un porcentaje elevado de superficie, permaneciendo sólo algunos restos de ella en las partes externas de los abultamientos que definen los micro-relieves. El estudio del índice de esclerometría muestra una clara correlación entre zonas con y sin costra, con un valor medio de 35 en las superficies endurecidas y de 26 en las zonas 
alteradas en las que ha sido eliminada por completo. Los valores máximos del índice de esclerometría se localizan sobre las placas de los agrietamientos poligonales, donde el espesor de la superficie endurecida es mayor, seguida de la zona inferior del muro donde la superficie ocupada por costra es amplia aunque de menor espesor que en la zona superior. En cuanto a la temperatura se ha constatado que las mayores oscilaciones térmicas ocurren en la zona superior, decreciendo hacia la base de la pared, presentando una buena correlación con la superficie ocupada por superficie endurecida.

\section{Agradecimientos}

Este estudio ha sido financiado por la Comunidad de Madrid a través del Programa Geomateriales 2 (S2013/ MIT-2914). Los autores agradecen las correcciones y sugerencias de dos revisores anónimos que han ayudado a mejorar el trabajo.

\section{Referencias}

Avdelidis, N.P., Moropoulou, A., 2003, Emissivity considerations in building thermography: Energy and Buildings, 35, 663-667.

Bradley, W.C, Hutton, J.T., Twidale, C.R., 1978, Role of salts in development of granitic tafoni, South Australia: Journal of Geology, $86,647-654$.

Branagan, D.F., 1983, Tesselated pavements, en Aspects of Australian sandstone landscapes, Young, R.W., Nanson, G.C. (eds.), Australian and New Zealand Geomorphology Group Special Publication $\mathrm{n}^{\circ} 1$, Wollongong, 11-20.

Campbell, E.M., Twidale, C.R., 1995, Lithologic and climatic convergence in granite morphology: Cadernos do Laboratorio Xeolóxico de Laxe 20, 381-403.

Centeno J.D., 1988, Morfología granítica de un sector del Guadarrama Occidental: Madrid, España, Editorial Complutense, Colección Tesis Doctorales n $262 / 88,432 \mathrm{p}$.

Conca, J.L., 1985, Differential weathering effects and mechanisms: Pasadena, California, California Institute of Technology, Dissertation Thesis, $251 \mathrm{p}$.

De Prado, C. (1864), 1975, Descripción física y geológica de la provincia de Madrid: Madrid, España, Publicaciones especiales Colegio de Ingenieros de Caminos, Canales y Puertos, 325 p.

Dorn, R.I., 1998, Rock coatings: Developments in Earth Surface Processes 6,429 .

García-Rodríguez, M., Centeno, J.D., Alvarez de Buergo, M., 2012, Weathering landforms exposure and erosion phases in Pedriza de Manzanares (Spanish Central Range): Geophysical Research Abstracts, EGU General Assembly, Viena, 14, EGU2012-6279-1.

García-Rodríguez, M., Centeno, J.D., Gómez-Heras, M., Fort González, R., Alvarez de Buergo, M., 2013, Thermal and structural controls on polygonal cracking in granite of La Pedriza de Manzanares (Spain), Abstracts Volume $8^{\text {th }}$ International Conference (AIG) on Geomorphology: Geomorphology and Sustainability, 27-31, 303.

García-Rodríguez, M., Centeno, J.D., 2014, Identificación de fases erosivas en La Pedriza de Manzanares a partir de formas de alteración expuestas: Tecnologi@y Desarrollo, UAX, XII, 20 p.

García-Rodríguez, M., Gómez-Heras, M., Fort González, R., Alvarez de Buergo, M., Centeno, J.D., 2014a, Influencia de los endurecimientos superficiales en el micro-relieve de las superficies graníticas de La Pedriza de Manzanares. Parque Nacional de Guadarrama (España): Tecnologi@ y Desarrollo, UAX, XII, 23 p.
García-Rodríguez, M., Gómez-Heras, M., Alvarez de Buergo, M., Fort González, R., Centeno, J.D., 2014b, Caracterización de agrietamientos poligonales sobre granito en La Pedriza de Manzanares y en Cenicientos, Madrid (Sistema Central): Revista M+A, 15 (1), 22-36, doi 10.5209/rev_MARE.2014.v15.n1.45567.

García-Rodríguez, M., García Rodríguez, M, Salcedo Miranda, J.L., 2014c, "El Hueso" de la Pedriza: origen, estructura y rasgos geomorfológicos: Tecnologí@ y Desarrollo, UAX, XII. 20 p.

Garner, H.F., 1974, The origin of landscapes, a synthesis of geomorphology: New York, Oxford University Press, 734 p.

Gómez-Heras, M., Smith, B.J., Fort R., 2006, Surface temperature differences between minerals in crystalline rocks: Implications for granular disaggregation of granites through thermal fatigue: Geomorphology 78 (3-4), 236-249.

Gómez-Heras, M., Smith, B.J., Fort, R., 2008, Influence of surface heterogeneities of building granite on its thermal response and its potential for the generation of thermoclasty: Environmental Geology $56(3-4), 547-560$.

Gómez-Heras, M., McAllister, D., Gómez-Flechoso, M.A., Fort, R., GarcíaMorales, S., 2014, Ejemplos de análisis cuantitativo de imágenes de infrarrojos obtenidas por termografía activa para la detección de patologías de humedades: Actas del Congreso Latinoamericano sobre Patología de la construcción, tecnología de la rehabilitación y gestión del patrimonio, REHABEND, 2014, 461-468.

Goudie, A.S., Migon, P., 1997, Weathering pits in the Spitzkoppe area, Central Namib Desert: Zeitschift für Geomorphologie, 41 (4), 417-444.

Goudie, A.S., 2006, The Schmidt Hammer in geomorphological research: Progress in Physical Geography, 30 (6), 703-718.

Hall, K., André, M.F., 2003, Rock thermal data at the grain scale: applicability to granular disintegration in cold environments: Earth Surface Processes and Landforms 28, 823-836.

Hobbs, W.H., 1912, Earth features and their meaning. An introduction to geology for the students and the general reader: New York, The Macmillan company, $491 \mathrm{p}$.

Instituto Geológico y Minero de España, IGME, 1988, Atlas Geocientífico del Medio Natural de la Comunidad de Madrid: Madrid, España, IGME, $83 \mathrm{p}$.

Ishimaru, S., Yoshikawa, K., 2000, The weathering of granodiorite porphyry in the Thiel Mountains, inland Antartica: Geografiska Annaler, 82A, 45-57.

Klein, M.T., Ibarra-Castanedo, C., Maldague, XP., Bendada, A., 2008, A straightforward graphical user interface for basic and advanced signal processing of thermographic infrared sequences, en Vavilov, V.P., Douglas, D., Burleigh, D., (eds.), Thermosense XXX, Proceedings of SPIE, 6939, 693914.

Matsukura, Y., Tanaka, Y., 2000, Effect of rock hardness and moisture content on tafoni weathering in the granite of Mount Doeg-Sung, Korea: Geografiska Annaler, Series A, Physical Geography, 82, $59-67$.

Merrill, G.P., 1906, A treatise on rocks, rock weathering, and soils, New York, MacMillan, $400 \mathrm{p}$.

Molina-Ballesteros, E., García-Talegón, J., Vicente-Hernández, M.A., 1997, Palaeoweathering profiles developed upon the Iberian Hercynian Basement: their relationship to the oldest Tertiary surface in Central and Western Spain, en Widdowson, M (ed), Tertiary and pre-tertiary Palaeosurfaces: recognition, reconstruction and environmental implications: Geological Society of London, Geological Society of London, Special Publication 120, 175-185.

Mottershead, D.N., Pye, K., 1994, Tafoni on coast slopes, South Devon, U.K: Earth Surface Processes and Landforms, 19, 543-563.

Pedraza, J., 1989, La morfogénesis del Sistema Central y su relación con la morfología granítica. Morphogenesis of the central range (Spain) and its relation with granite morphologies: Cadernos do Laboratorio Xeolóxico de Laxe, 13, 31-46.

Pedraza, J., Sanz, M.A, Martín, A., 1989, Formas graníticas de La Pedriza. Agencia de Medio Ambiente: Madrid, España, Comunidad de Madrid, $205 \mathrm{p}$. 
Pedraza, J., Carrasco M.R., Domínguez-Villar, D., 2014, Geomorphology of La Pedriza Granitic Massif, Guadarrama Range, en Gutiérrez, F., Gutiérrez, M., (eds), Landscape and Landforms of Spain, Springer, 71-80.

Pérez-Soba, C.,Villaseca, C., 2010, Petrogenesis of highly fractionated I-type peraluminous granites: La Pedriza pluton (Spanish Central System): Geologica Acta, 8, 131-149.

Rice, A., 1976, Insolation warmed over: Geology, 4, 61-62.

Riley, P, Murray, A.B, Tikoff, B., 2012, Geometric scale invariance, genesis, and self-organization of polygonal fracture networks in granitic rocks: Journal of Structural Geology, 42, 34-48.

Robinson, D.A., Williams, R.B.G., 1987, Surface crusting of sandstones in southern England and northern France, en Gardiner, V., (ed.), International Geomorphology 1986 Part II, Wiley \& sons, 623-635.

Robinson, D.A., Williams, R.B.G., 1989, Polygonal cracking of sandstone at Fontainebleu, France: Zeitschrift für Geomorphologie, 33, 59-72.

Robinson, D.A., Williams, R.B.G., 1992, Sandstone weathering in the High Atlas, Marocco: Zeitschrift fur Geomorphologie, 36, 413-429.

Schulke, H., 1973, Schildkrotenmuster'und andere Polygonalstrukturen auf Felsoberflächen: Zeitschrift für Geomorphologie, 17, 474-488.

Smith, B.J., 1977, Rock temperature measurements from the northwest Sahara and their implications for rock weathering: Catena, 4 (1-2), 41-63.

Sosman, R.B., 1916, Types of prismatic structure in igneous rocks: Journal of Geology, 24, 215-234.
Twidale, C.R., 1982, Granite Landforms: Amsterdam, Elsevier, 372 p

Van Auternboer, T., 1964, The geomorphology and glacial geology of Sor Rondane, Dronning Maud Land, en Adie, R., (ed.), Antartic geology: Amsterdam, North Holland, 81-103.

Vidal Romani, J.R., Twidale, C.R., 2010, Structural or climatic control in granite landforms? The development of sheet structure, foliation, boudinage, and related features: Cadernos do Laboratorio Xeolóxico de Laxe, 35, 189-208.

Viles, H.A., Goudie, A.S., 2004, Biofilms and case hardening on sandstones from Al-Quwayra, Jordan: Earth Surface Processes and landforms, 29, 1473-1485.

Watson, A., Pye, K., 1985, Pseudokarstic micro-relief and other weathering features on the Mswati Granite (Swaziland): Zeitschrift fur Geomorphologie, 29, 285-300.

Wilhelmy, H., 1964, Cavernous rock surfaces in semi-arid and arid climates: Pakistan Geographical Review, 19 (2), 8-13.

Young, A.R.M., 1987, Salt as an agent in the development of cavernous weathering: Geology, 15 (10), 962-966.

Manuscrito recibido: Mayo 21, 2015.

Manuscrito corregido recibido: Julio 14, 2015.

Manuscrito aceptado: Julio 20, 2015. 